\title{
Effectiveness of Acquiring of Basic Verbs by Using Core Schema-Based Instruction
}

\author{
Masanobu Sato
}

\begin{abstract}
This study compared schema-based instruction and translation-based instruction with regard to the learning of basic visual verbs of perception, look and see. Overall, the results show that $\mathrm{SBI}$ is as effective as TBI in the short run and more effective than TBI in the long run.
\end{abstract}

Index Terms-Lexical acquisition, schema-based instruction, memory retention.

\section{INTRODUCTION}

This study compares two types of instruction: schema-based instruction (SBI) and translation-based instruction (TBI). The question here is which type is more effective in teaching the selective use of look and see. TBI is a widely used conventional way of teaching L2 vocabulary. The teacher is generally concerned with how many words the student knows. He or she tends to pay less attention to the depth of vocabulary. From the learner's point of view, it is a type of "deliberative vocabulary learning" [1]. Typically, a learner uses a word list, and tries to memorize the meaning and usage of a word in question. By focusing on a set of words presented in a simple format, the learner is able to handle many words in a comparatively short period of learning time. The learner's attention is paid exclusively to the targeted words. Given 20 words a day, for example, the learner will somehow memorize their meanings and usages as a "checkup list." If a word has three meanings, the learner will treat them as if they were different items on the list. The learner memorizes them and produces them as they have been memorized. Simply put, "what comes in goes out" is a model of TBI.

In this study, we are interested in the effects of SBI on lexical learning. The notion of "schema" in this study refers to the "core schema" of a word [2]-[4]. Core schema, or simply "schema," functions as the common thread of different meanings in a polysemous word [5]. SBI encourages students to understand how seemingly different usages are linked through the underlying core schema of a word. The use of SBI assumes that the student does not simply take a given usage of a word as it is, but rather goes beyond it, exercising a semantic analysis of how the usage is related to the schema. This mental exercise will presumably lead to deeper processing and better learning.

There are some previous studies dealing with the comparative effects of TBI and SBI on lexical acquisition. [6] did a quasi-experimental study with 58 Japanese high school

Manuscript received August 19, 2014; revised January 20, 2015.

Masanobu Sato is with the Keio University, Japan (e-mail kizuna238@yahoo.co.jp). students, who were divided into two treatment groups. The experiment group and the control group received SBI and TBI regarding the verb break and the preposition over, respectively, for 20 minutes. The pretest was administered prior to instruction. They administered the posttest- 1 two days after the instruction and the posttest- 2 two weeks after. Morimoto and Loewen reported that SBI was as effective as TBI both in acceptability judgment and production tests. The target words were the verb arriver and the preposition sur in French. The overall results showed that SBI and TBI are equally effective in acceptability judgment test, and SBI gained better results for production test. Both studies suggest that lexical schema is a promising device in teaching L2 lexicon. These were, however, quasi-experimental studies with no detailed procedures, and as Morimoto and Loewen suggest, the findings are far from conclusive, and still require theoretical accounts.

Regarding the question of why the use of schema can be an effective device, we will be able to explain it with reference to memory. Memory is an interface of language learning and cognition [7]. Forgetting is unavoidable, and less activated information tend to be forgotten easily [8]. Generally, as the Ebbinghaus forgetting curb hypothesis suggests, memory retention declines in time. If there is no attempt to retain information, it will be lost. In other words, rehearsal strengthens memory. If the usage of a word is processed and understood through the core schema, we expect that the core schema processing activates mental activities on the part of the learner, which makes deeper information processing possible, which, in turn, leads to better memory retention.

On the basis of the findings of the previous studies mentioned here, we formulate the hypothesis that schema-based instruction is as effective as translation-based instruction in teaching basic words in English. Testing this hypothesis is a replication of the previous studies, giving further evidence to the effects of SBI on lexical learning. This study is interested in another hypothesis that schema-based instruction leads to the better output with respect to memory retention. This study, then, tests the following two-fold hypotheses: (1) Schema-based instruction is as effective as translation-based instruction in teaching L2 basic words in the short run, and (2) Schema-based instruction is more effective than translation-based instruction in the long run with respect to memory retention.

\section{THE TARGET OF THIS STUDY}

The target of this study is the lexical domain of visual perception, of which the basic verbs, look and see, are chosen. These two are introduced to Japanese students in early stages of English learning. However, the acquisition of these verbs 
is far from easy [9]. Acquisition of these verbs involves the learning of interlexical competence (i.e., the ability to use look and see differentially) as well as intralexical competence (i.e., the ability to use look or see fully). For the latter, this study considered the following 10 dictionary meanings associated with the verb see: (1) "Perceive with the eye": In the distance I can see a blue mountain. / (2) "To view as a spectator": I'm going to see a kabuki play this Saturday. / (3) "To perceive things mentally (understand)": It seems that the headmaster was not able to see the joke. / (4) "To suppose as acceptable or as a possibility": I can't see Rex as president. / (5) "To discover": I generally see the good in others. / (6) "To experience": I hope to see the day when injustice disappears. /

(7) "To meet with": Are you seeing Mr. James at lunch today? / (8) "To date frequently": Bob and Mary have been seeing each other. / (9) “To escort": It's getting late, but don't worry. I'll see you home. / (10) "To witness": The 20th century saw the landing of humans on the moon.

Comparatively, the verb look is less polysemous than see. In this study, we considered the following five dictionary meanings: (1) "To turn one's eyes toward something": They looked at me. / (2) "To direct attention or consideration": Let us look at the facts in detail. / (3) "To face or front": I want to buy a house that looks to the east. / (4) "To expect or anticipate": They're looking to win back some lost profits. / (5) "To turn one's attention": Look what time it is.

Underlying these dictionary meanings, we assume the core schema of see and look, which can be schematically expressed as follows:

The core schema of see is a visual representation of the core meaning of "having the visual sense organ work in order to capture the target." The verb assumes the functioning of one's eyes; that is, to capture the sight of something, one's eyes must properly function. Thus, we have expressions like "I'm wondering if just born babies can see," which highlight the functioning of one's eyes. On the other hand, sentences like "I saw a beautiful lake there" and "I see what you mean" focus on the feature of "capturing the object." In the latter example, we take it metaphorically that to understand something is to see something.

The schema of look captures the core meaning of "directing visual attention to something." If you turn your eyes to something, you are attending visual attention to it. The schematic image can be projected, for example, to the case of "a house looking to the east." The core schema of look seems simple, and yet, it has explanatory power. From the schema, we know that: (1) the verb look is a dynamic verb, which can take a progressive form as in "John is looking at the sea;" (2) in order to see something, one needs to look at something first. Thus, "Look and see what's going on outside" is a natural sequence, while the order of "see and look" sounds strange, and (3) the core meaning of look (i.e., "turning one's eyes") suggests that the verb normally requires a preposition or spatial adverb to indicate the direction or goal of the eye's movement, as in "look down," "look over," "look back," and "look through."

In order to master the selective use of look and see, students need to learn not only how to use them differentially, but also how to use each of them fully. The question is whether SBI is effective in teaching English basic verbs to Japanese students in instructional settings.

\section{METHOD}

Two groups of university students, 18 students each, participated in this experiment. Two groups were considered at the same level of English proficiency when the experiment started. Both belonged to the lower-intermediate level within the university. One of the groups, the experimental group received SBI, while the other group, the control group, received the treatment of TBI. The design utilized in this study was the pretest, posttest, control group design.

In the pretest, the participants were asked to choose either look or see depending on the context given in Japanese, as in the following format:

The participants were also asked to rate their level of confidence on a 5-point scale when choosing the answer for each item. In total, the test has 14 items, of which the 9 items required see as the answer, the 3 items required look, and the remaining two were distractors. More see items were included than look items, in that see is considerably more polysemous than look. For this test, the meanings and their examples for each verb were selected within the polysemous range as shown above (10 meanings for see, and 5 meanings for look). The posttest- 1 was designed exactly in the same format as the pretest, and the dictionary meanings represented by examples remained the same; only the examples for each verb were different. The posttest- 2 took the same format, and yet, it consisted of 35 items (20 items for see, 10 items for look, and 5 distractors). The posttest-2 contained 7 new items in addition to the items presented in the pretest (14 items) and the posttest-1 (14 items). To be more specific, the posttest- 2 had 20 items representing the 10 meanings for see, 10 items representing the 5 meanings for look, and 5 distractor items.

One week after the pretest, 90-minutes instruction was given to the experimental group and the control group on the same day by the author himself. Both SBI and TBI were given with the use of PowerPoint slides on the screen. The 14 items in the pretest were used as the teaching materials in both types of instruction. The description below sketches how each instruction proceeded.

Immediately after the instruction, the teacher announced that the class would take a comprehension-check test the next week, and that each of the students should prepare for it with a review sheet distributed in class. We assumed that 90-minutes instruction alone does not suffice to bring about instructional effects on lexical learning. Less activated information tends to be forgotten, and we considered that the student's working on the review sheet becomes a rehearsing for the posttest-1. The comparison between the pretest and the posttest-1 tests our "weak" hypothesis that schema-based instruction is as effective as translation-based instruction in teaching basic words in English. We had a "stronger" hypothesis that schema-based instruction leads to the better output with respect to memory retention. To test the stronger hypothesis, we administered the posttest- 2 one week after the posttest-1, with no prior announcement.

\section{RESULTS AND DISCUSSION}

The overall results of the three tests are given in Table I. Considering the different numbers of test items between the posttest-1 (12 plus 2 distractors) plus 5 distractors), the 
results are all shown in percentages of correct answers. Examination of pretest means indicated that the groups were essentially the same at the beginning of the study ( $t$ (34) $=0.226$, ns). Following the treatment, the posttest- 1 was administered to the two groups. For the SBI group, the difference between the pretest scores and the posttest-1 scores was statistically significant $(t(17)=5.082, p<.001)$. The same went for the TBI group $(t(17)=5.507, p<0.01)$. The TBI group did slightly better than the SBI group in the posttest-1, although the difference was not statistically significant $(t(34)=0.924, \mathrm{~ns})$. In the posttest-2, the SBI group $(62.67 \%)$ did better than the TBI group $(59.33 \%)$, though the difference did not reach the significant level $(t$ (34) $=0.628, \mathrm{~ns})$.

\begin{tabular}{|c|c|c|}
\hline & GROUPS (MEAN & \\
\hline & SBI & TBI \\
\hline Pretest & $36.67(2.60)$ & 35.83 \\
\hline Posttest-1 & $55.50(3.02)$ & $59.44(3.30)$ \\
\hline Posttest-2 & $62.67(3.75)$ & $59.33(3.80)$ \\
\hline
\end{tabular}

The interesting point to notice is that both groups benefitted from instruction in the short run, as shown in the comparison between the pretest scores and the posttest-1 scores, thus supporting the weak hypothesis. Two weeks after the instruction, however, the overall performance of the SBI group went up from $55.5 \%$ to $62.7 \%$, whereas the performance of the TBI $(59.4 \%$ in the posttest 1 and $59.3 \%$ in the posttest-2) leveled off.

In this study, we asked each participant to rate his or her level of confidence in answering each question. We expected that the level of confidence in using the target language would be influenced by the type of instruction. Table II shows how their level of confidence (expressed in percentages) shifted across the three tests we administered.

TABLE II: THE CONFIDENCE LEVEL, THE SBI AND TBI GROUPS IN THREE

\begin{tabular}{|c|c|c|}
\hline \multicolumn{3}{|c|}{ TESTS } \\
\hline Group & SBI & TBI \\
\hline Pretest & $59 \%$ & $56 \%$ \\
\hline Posttest-1 & $67 \%$ & $60 \%$ \\
\hline Posttest-2 & $60 \%$ & $55 \%$ \\
\hline
\end{tabular}

Overall, the SBI group rated their confidence level higher than the TBI group, especially in taking the posttest-1. The SBI group was taught the core schemas of look and see, and their understanding of them might have helped them answer the questions in the posttest-1. In the posttest-2, however, their confidence level decreased in both groups, probably because they were not allowed to prepare for the test and the posttest- 2 contained items more than twice as many as the pretest or the posttest-1.

The case of see:

Let us now take a closer look at the results at the example level. Table III shows the results from the pretest and the posttest-1.

In the pretest, the see-related items obtained high scores and low scores are similar between the experimental and control groups (compare the best two items and the worst 3 items). In the posttest-1, the best two items and the worst one item remain the same between the two groups.

For a more detailed analysis, let us take a look at the see-related items in the posttest- 2 in terms of the rank order of difficulty. The test contained 20 examples of see, with the results being shown in Table IV.

TABLE III: THE CORRECT \% OF LEXICAL SELECTION IN THE PRETEST AND POSTTEST-1 ITEMS

\begin{tabular}{lcc} 
The Pretest & SBI group & TBI group \\
In the distance I can see a blue mountain. & $59 \%$ & $53 \%$ \\
I'm going to see a kabuki this Saturday & $53 \%$ & $58 \%$ \\
I hope to see the day when injustice disappears & $53 \%$ & $42 \%$ \\
I've never seen a perfect eclipse before. & $47 \%$ & $53 \%$ \\
I can't see Rex as president. & $42 \%$ & $42 \%$ \\
You'd better see the world. & $32 \%$ & $26 \%$ \\
It seems that the headmaster was not able to see & & \\
the joke. & $26 \%$ & $21 \%$ \\
$\begin{array}{l}\text { It's getting late, but don't worry. I'll see you } \\
\text { home. }\end{array}$ & $26 \%$ & $26 \%$ \\
$\begin{array}{l}\text { We've been seeing each other for a long time. } \\
\text { The Posttest-1 }\end{array}$ & $21 \%$ & $26 \%$ \\
$\begin{array}{l}\text { Are you seeing Mr. James at lunch today? } \\
\text { You see the mistakes you make after you have } \\
\text { made them. }\end{array}$ & $79 \%$ & $84 \%$ \\
$\begin{array}{l}\text { You should go and see a counselor. } \\
\text { I asked Billy to see Prof. Brown to the door. }\end{array}$ & $74 \%$ & $74 \%$ \\
$\begin{array}{l}\text { The 20th century saw the landing of humans } \\
\text { on the moon. }\end{array}$ & $68 \%$ & $58 \%$ \\
$\begin{array}{l}\text { The 1970s saw an incredible economic boom. } \\
\text { I generally see the good in others. }\end{array}$ & $42 \%$ & $68 \%$ \\
\hline
\end{tabular}

TABLE IV: THE CORRECT \% OF LEXICAL SELECTION IN THE POSTTEST-2 BETWEEN SBI AND TBI GROUPS

\begin{tabular}{lcc} 
The Posttest-2 & SBI & TBI \\
\hline I can't see Rex as president. & $90 \%$ & $63 \%$ \\
I've never seen a perfect eclipse before. & $84 \%$ & $74 \%$ \\
Are you seeing Mr. James at lunch today? & $84 \%$ & $74 \%$ \\
We've been seeing each other for a long time. & $79 \%$ & $74 \%$ \\
I asked Billy to see Prof. Brown to the door. & $79 \%$ & $69 \%$ \\
In the distance I can see a blue mountain. & $74 \%$ & $63 \%$ \\
I'm going to see a kabuki play this Saturday. & $74 \%$ & $58 \%$ \\
Before long they started seeing each other regularly. & $74 \%$ & $58 \%$ \\
It's getting late. But don't worry. I'll see you home. & $74 \%$ & $79 \%$ \\
I hope to see the day when injustice disappears. & $68 \%$ & $44 \%$ \\
You should go and see a counselor. & $68 \%$ & $53 \%$ \\
It seems that the headmaster was not able to see the joke. $63 \%$ & $42 \%$ \\
I can't stand to see you so unhappy. & $63 \%$ & $90 \%$ \\
I generally see the good in others. & $63 \%$ & $58 \%$ \\
Spectators can see the some live entertainment. & $58 \%$ & $58 \%$ \\
I just want a person to see in me something that's in them. 58\% & $53 \%$ \\
You see the mistakes you make after you have made & & \\
them. & $53 \%$ & $74 \%$ \\
The 1970s saw an incredible economic boom. & $53 \%$ & $63 \%$ \\
You'd better see the world. & $47 \%$ & $53 \%$ \\
The 20th century saw the landing of humans on the moon. 47\% & $63 \%$ \\
\hline
\end{tabular}

The SBI group did best on the item "I can't see Rex as president." When the same item appeared in the pretest, $42 \%$ of the participants answered correctly. The posttest- 2 saw a big leap (from $42 \%$ to $90 \%$ ). This leap was not observed in the TBI group. Presumably, the SBI group must have perceived the best fit between the core schema of see and this usage of see. The post-interview with some participants in the SBI group confirmed this point, which seems to suggest that the cognitive operation of schema projection is constrained by the learner's perceived distance between their internalized schema and the state of affairs expressed in an example sentence. For example, "The 20th century saw the landing of humans on the moon" was the worst item for the SBI group. The subject of this sentence is "the 20th century," which does not have the "eye" to capture the event "the landing of humans." Interestingly, this item appeared in the posttest-1, and $68 \%$ of the SBI group answered it correctly. In the posttest-2, the percentage reduced to $47 \%$. At the time of 
treatment, it was instructed that "the 20th century" in "The 20 th century saw the landing of humans on the moon" should be interpreted metaphorically or in a personified way. This instruction worked for a short period of time when the group took the posttest-1 (68\%), but the effect tapered off along with time (53\%). We assume that the rather abstract instruction, "It should be interpreted metaphorically," did not suffice to convince students of the link between the core schema and the example.

"You'd better see the world" is an idiomatic expression with the meaning of "experience the world." This item failed to obtain a good effect of schema-based instruction. Here again, "the world" is not a clear-cut object, and hence, the operation of schema projection does not apply straightforwardly. By contrast, "I hope to see the day when injustice disappears," though a similar example of the same semantic type, received $68 \%$ correct among the SBI group (the TBI group obtained $44 \%$ correct). The different results obtained from "see the world" and "see the day" among the SBI group are accountable in terms of the learner's perceived distance from the core schema of see.

In dealing with the item "The 20th century saw the landing of humans on the moon," the TBI group did fairly good both on the posttest-1 (74\%) and the posttest-2 (63\%). This is because they memorized it as a distinct example of see, or they took it that the verb see has a meaning of "witness." Even in the case of the idiomatic expression "You'd better see the world," the TBI group memorizes the use of see here meaning "experience." As long as the memory lasts, we expect that what comes in simply goes out, thus resulting in a good outcome $(26 \%$ correct in the pretest vs. $53 \%$ correct in the posttest-2). The same story holds in the case of "You see the mistakes you make after you have made them," which is syntactically a little challenging. The TBI group's performance was constant between the posttest-1 $(74 \%)$ and posttest-2 (74\%). The correct percentage $(53 \%)$ of the SBI group failed to reach the TBI's high level. Presumably, the syntactic complexity makes the SBI group difficult to apply the core schema of see to this case.

The case of look:

Considering the degree of polysemy, the verb look did not contain as many items as the verb see. The overall results of the three tests are shown in Table V.

First, let us pay attention to the item which obtained the highest percentage (79\%) for the two groups in the posttest-2, that is, "I want to buy a house which looks to the east." In the pretest, this item received a low percentage: $32 \%$ for the SBI group and $21 \%$ for the TBI group. In schema-based instruction, the application of the core schema of look is not straightforward because the subject (i.e., a house) is an inanimate object which does not intrinsically have eyes. However, the usage must have been totally new to the participants. There was a response "I didn't know that look is used this way." The participants paid attention to this form, and the item became a salient example. Speculatively, what we call "exemplar saliency" explains the high score for "I want to buy a house which looks to the east" for the SBI group. However, here again, "exemplar saliency" does not necessarily guarantee the generalizing power of the core schema. In other words, the following two sentences are of the same semantic type: "I want to buy a house which looks to the east" and "The window looks upon the street." The item "The window looks upon the street" received only $42 \%$ for the SBI group, which means that the group failed to apply the core schema, which successfully applied to the "house" case, to the "the window" case. Likewise, the cases of "Look what time it is" and "You really should look where you are going" belong to the same semantic type. However, as the different correct percentages suggest, unless pedagogical attention is paid to the "look where you are going" case, students have trouble in using their core schema. In contrast, the "look what time it is" case is colloquially often used and taught in school. Thus, it is likely that the participants of this study had encountered the example before they took the test, while they experienced the "look where you are going" for the first time in the test.

TABLE V: COMPARISON BETWEEN THE SBI AND THE TBI GROUPS WITH RESPECT TO THE CORRECT \% OF LEXICAL SELECTION IN THE PRETEST, THE POSTTEST-1, AND THE POSTTEST-2

\begin{tabular}{lcc} 
The Pretest & SBI & TBI \\
\hline Let us look at the facts in detail. & $52 \%$ & $47 \%$ \\
I want to purchase a house which looks to the east. & $32 \%$ & $21 \%$ \\
They are looking to win back some lost profits11\% & $16 \%$ & \\
The Posttest-1 & SBI & TBI \\
\hline The committee is looking at the financing of the & & \\
company. & $69 \%$ & $53 \%$ \\
People were looking at me suspiciously. & $57 \%$ & $43 \%$ \\
The window looked upon the street. & $32 \%$ & $68 \%$ \\
I looked hard in the dark, but I was not able to & & \\
find anyone. & $26 \%$ & $43 \%$ \\
The Posttest-2 & SBI & TBI \\
\hline I want to purchase a house which looks to the east. & $79 \%$ & $79 \%$ \\
People were looking at me suspiciously. & $67 \%$ & $37 \%$ \\
Look what time it is. & $63 \%$ & $68 \%$ \\
The committee is looking at the financing of the & & \\
company. & $59 \%$ & $47 \%$ \\
Let us look at the facts in detail. & $53 \%$ & $74 \%$ \\
They're looking to win back some lost profits & $53 \%$ & $26 \%$ \\
I looked hard in the dark, but I was not able to & & \\
find anyone. & $42 \%$ & $58 \%$ \\
The window looked upon the street. & $42 \%$ & $63 \%$ \\
You really should look where you're going. & $42 \%$ & $47 \%$ \\
The mayor is looking to reduce the crime rate. & $37 \%$ & $37 \%$ \\
\hline
\end{tabular}

First, let us pay attention to the item which obtained the highest percentage (79\%) for the two groups in the posttest-2, that is, "I want to buy a house which looks to the east." In the pretest, this item received a low percentage: $32 \%$ for the SBI group and $21 \%$ for the TBI group. In schema-based instruction, the application of the core schema of look is not straightforward because the subject (i.e., a house) is an inanimate object which does not intrinsically have eyes. However, the usage must have been totally new to the participants. There was a response "I didn't know that look is used this way." The participants paid attention to this form, and the item became a salient example. Speculatively, what we call "exemplar saliency" explains the high score for "I want to buy a house which looks to the east" for the SBI group. However, here again, "exemplar saliency" does not necessarily guarantee the generalizing power of the core schema. In other words, the following two sentences are of the same semantic type: "I want to buy a house which looks to the east" and "The window looks upon the street." The item "The window looks upon the street" received only $42 \%$ for the SBI group, which means that the group failed to apply the core schema, which successfully applied to the "house" case, to the "the window" case. Likewise, the cases of "Look what time it is" and "You really should look where you are 
going" belong to the same semantic type. However, as the different correct percentages suggest, unless pedagogical attention is paid to the "look where you are going" case, students have trouble in using their core schema. In contrast, the "look what time it is" case is colloquially often used and taught in school. Thus, it is likely that the participants of this study had encountered the example before they took the test, while they experienced the "look where you are going" for the first time in the test.

\section{PedagogicAl ImPlicAtions}

Translation-based instruction helps students accumulate a stock of meanings in the form of English-to-Japanese matching with examples. The effect of TBI depends on the activation of the learned information. In other words, as long as the memorized examples remain salient, TBI becomes an effective teaching method. However, as the number of examples increase, the forgetting curve is a demanding challenge on the part of the learner.

SBI potentially contributes to the building of both intra-lexical and inter-lexical networks. To select see over look in a new situation, for example, the learner needs to know the essential difference between see and look, which reduces to the difference at the core schema level. The use of core schema (i.e., pictorial representation) helps students personalize the meanings of a target word.

Ref. [10] studied whether the use of a picture-drawing technique helps students learn English vocabulary. Given words such as "true," quick," and "surprised," a Japanese student easily comes up with the translation equivalent for each target word. Anderson argues that when we ask students to draw pictures which may illustrate their interpreted meanings, we are giving them opportunities to personalize the word meaning, which, in turn, leads to deeper lexical understanding. Thus, drawing pictures becomes an effective learning strategy. The technique can be used to teach basic verbs like look and see. Instead of giving students the core schema of look, for example, we encourage them to draw their schemas both at the context-independent and context-sensitive levels. [10] claims that it also becomes an effective pedagogical or teaching strategy when it is linked with feedback, and uses the term "formative feedback," which is defined as feedback that drives the student to move forward in the pedagogical or real task he or she is engaged in. Anderson correctly points out that the student's pictures can become good foci for formative feedback. Some pictures are just apt and semantically transparent, and some are otherwise. Semantically opaque pictures motivate verbal interaction.

However, the problem with SBI is that some examples are easy to be processed through core schema, while others are not. Filling the gap (i.e., the learner's perceived distance) between the core schema and the example in question, the teacher should require a high degree of expertise in explaining how the schema applies to the example persuasively. In conducting the experiment in this study, I personally experienced that for some examples, I was confidently able to relate to the core schema and for others, I was barely able to give ad-hoc accounts. For the former, students' reactions were positive with a lot of nods. For the latter, their reactions were ambiguous with puzzled looks.

\section{CONCLUSION}

This study tested the hypothesis that SBI is as effective as TBI in teaching L2 vocabulary (especially, basic words) in the short run. This was empirically supported, as with other previous studies [6]. We had a related hypothesis, which states that SBI is more effective than TBI in teaching basic words in the long run. Although the results did not reach the level of statistical significance, we found a strong tendency to support the hypothesis. We expect that future research gives us more convincing evidence to support this.

This study suggests that the effectiveness of SBI depends on factors such as exemplar saliency and transparency of schema projection onto examples. Whether the projection of the core schema onto examples is transparent highly depends on the teacher's expertise and understanding of the semantics of a given word. Future research is needed to differentiate hard examples from easy examples in terms of the usability of core schema in lexical instruction. How does the teacher present the core schema of a given word? When does he or she present it to students? What explanations should be given to obtain the maximum effect of SBI? These questions remain to be investigated.

\section{ACKNOWLEDGMENT}

I would like to express my gratitude to my academic advisor, Professor Shigenori Tanaka,Graduate School of Media and Governance at Keio University, for his support, patience, and encouragement throughout my research paper. His technical and editorial advice was essential to the completion of this research paper. He also read previous drafts of this paper and provided many valuable comments that improved the contents of this paper. I would like to thank him.

\section{REFERENCES}

[1] J. H. Hulstijn, "Incidental and intentional learning," in the Handbook of Second Language Acquisition, C. J. Doughty and M. H. Long, Eds. Malden, MA: Blackwell Publishing, 2003, pp. 349-381.

[2] G. Miller, "Semantic relations among words," in Linguistic Theory and Psychological Reality, M. Halle, J. Bresnan, and G. Miller, Eds. Cambridge, Mass: MIP Press, 1978, p. 78.

[3] C. Ruhl, Onmonosemy: A Study in Linguistic Semantics, Albany: State University of New York Press, 1989.

[4] S. Tanaka, Ninchi-Imiron: Eigodousi No Tagi No Kouzou (Cognitive Semantics: Structure of Verbal Polysemy in English), Tokyo: Sanyuusha, 1990, pp. 19-22

[5] D. Bollinger, Meaning and Form, London: Longman, 1977, p. 19.

[6] S. Morimoto and S. Loewen, "Comparison of the effects of image-schema-based instruction and translation-based instruction on the acquisition of L2 polysemous words," Language Teaching Research, vol. 11, no. 3, pp. 347-372, 2007.

[7] N. Schmitt, Vocabulary in Language Teaching, Cambridge, 2000.

[8] R. Gairns and S. Redman, Working with Words: A Guide to Teaching and Learning Vocabulary, Cambridge University Press, 1986.

[9] K. Hiki, "An exploratory study into second language learner knowledge of semantically similar lexical items: The case of verbs of perception," Indiana University, Bloomington IN, 1995.

[10] C. Anderson, "Utilizing student-generated pictures for formative vocabulary instruction," Vocabulary Learning and Instruction, vol. 1, pp. 37-43, 2012.

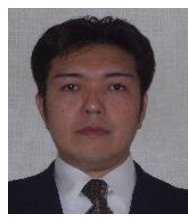

Masanobu Sato was born and raised in Japan. He has taught English at universities in Japan. He is now enrolled in the graduate program (Media \& Governance) at Keio University, writing his doctoral dissertation on L2 lexical development in Japan. His main research interests are second language acquisition, second language teaching methodology, English as a second language. 